\title{
A STUDY ON SMART CURRICULUM UTILIZING INTELLIGENT ROBOT SIMULATION
}

\author{
SeonYong Hong, Korea Advanced Institute of Science and Technology, gosyhong@kaist.ac.kr \\ YongHyun Hwang, University of California Irvine, freeaion@gmail.com
}

\begin{abstract}
Recently, science convergence education is emerging as a hot issue, which drives more attentions to education on a robot. The existing education on a robot is mainly about robot manipulation or robot assembly. The issue is that the education is standalone and, therefore, severely limits the effectiveness of education in terms of creativity and applicability. To maximize the effectiveness, the concept of convergence of other fields, such as math or art, should be introduced. This paper proposes a) SMART (Science, Math, Arts, Robot and Technology) curriculum utilizing intelligent robot simulation and b) methodology to realize intelligent robot creatively and its application. SMART curriculum helps a learner to express his/her infinite imagination in virtual $3 D$ world. Throughout the curriculum, it is expected that the learner can enhance capability of problem solving, creativity, and flexibility in thinking process. Because of this, it is strongly believed that SMART curriculum is becoming a next generation curriculum.
\end{abstract}

Keywords: SMART education, Intelligent Robot Education, Simulation Programming

\section{INTRODUCTION}

As importance on education process of a recent information technology grows, national wide methodology on how to obtain a creative human resource is actively being studied. In America and Europe, Convergence of science and technology education, so called STEM (Science, Technology, Engineering, Mathematics), had started to provide solid background on human resource development especially focusing on creativity. Recently, the nation has initiated the effort on STEM education, which is moving to STEAM (STEM + Arts) [1]. In 21th century, represented as knowledge-based era, education should pursue openness, innovation, fusion, and creativity. According to the recent foreign studies on excellent education process, lots of learning method for development of superior potentials is deployed to nurture a child as knowledge-based competent person. Finding a capable and creative person is important not only to a personal growth, but also to nation's competitive power. In such a global competitive education society, the nation strives to intend 'First Mover Education' instead of 'Fast Follower Education' to lead a future transition.

As such, education using a robot is becoming popular, which gives birth to various smart robot education methodologies. However, designing and programming a robot for education purpose requires lots of time and efforts, which is a critical drawback. In addition to this, educational purpose robot and robot education exposes problems on learner's creativity demonstration because of their limited object and application. Form and functions of a robot for education is getting close to a human. Example are 'entertainment robot', 'emotional robot', 'home service robot', 'educational robot', and 'health care robot'. However, all of them have their own program and parts, which cannot be used to other robot development. The biggest problem in smart robot development is that software technology is tightly coupled with hardware technology, where development of software or hardware for education purpose requires complex mathematical and scientific background [2].

To mitigate the issues explained above, this paper presents education process and methodology, called SMART (Science, Mathematics, Art, Robot, and Technology). The paper also proposes education design process to maximize education effect in learner's perspective. To validate paper's approach, SMART education process is exercised in a classroom and its results are carefully analyzed. This paper is organized as follows. Section 2 explains related works on robot education. Section 3 describes SMART education process design methodology based on intelligent robot simulation. In Section 4, a case study on learner education experiment is provided. In the last section, conclusion and future research direction are presented. 


\section{Issues in Information Systems}

Volume 13, Issue 2, pp.131-137, 2012

\section{Analysis on Education Methodology using a Robot}

The education using a robot can be categorized into two. The first one makes use of finished product robot to help a learner acquire knowledge. The methodology is especially effective to infants because a robot can bring curiosity and interest to them while delivering its contents smoothly. Therefore, robot based education (R-Learning) should put more importance on its content rather than its functionality [3][4]. Figure 1 shows an example of the R-Learning. In the example, a robot assistant teacher provides two way experience-based education systems for English class while interacting with children. However, the current technology for R-Learning requires big improvement in terms of vision, speech, and situation recognition technology.
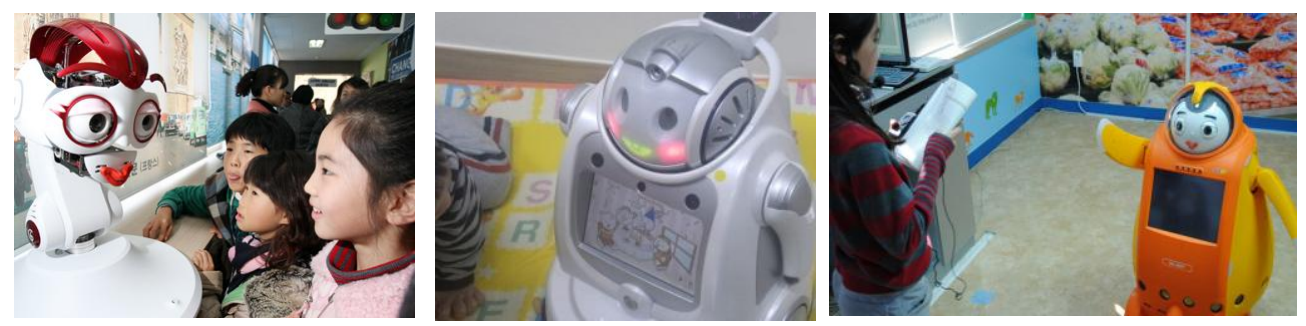

$<$ Figure 1> Teaching Assistant Robot

The second is educational robot education to produce a robot itself. While implementing a robot, a feature and principal of a robot can be obtained. Along with robot hardware, program is also developed, which provides deep knowledge on the robot. A robot designed for instruments of education is spread as a micro robot, line tracer, Humanoid, or Lego block assembly. Throughout the robot development, each robot requires its own software depending on its hardware property. This makes creation robot education challenging because teaching how to assemble a robot and use software to program the assembled robot requires lots of time and money. As shown in Figure 2, education process for a robot as instruments of education consists of a) robot model design, b) robot model production, c) robot programming, and d) robot action experiment. The second one, oriented in robot technology, is widely used as an education vehicle to improve problem solving ability, thinking ability, and creativity [5][6].

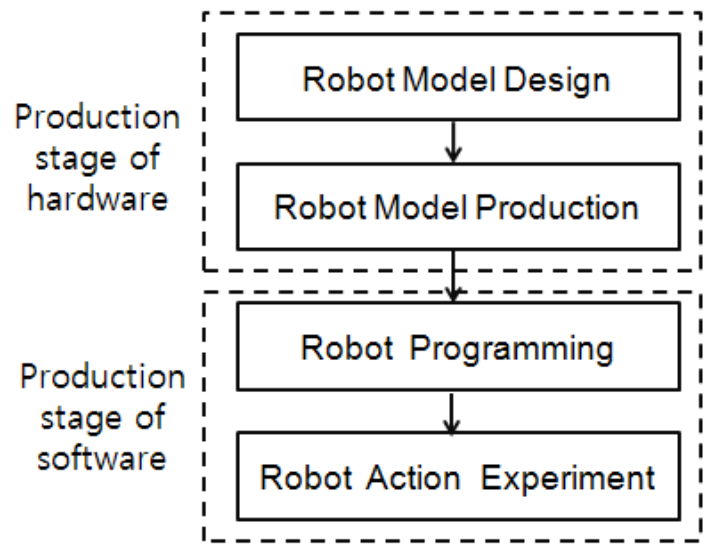

$<$ Figure 2> Education Process of a Robot as instruments of education

Especially, an education stage to program a robot is highly effective to provide better understanding on the property of robot hardware and develop logical/creative thinking. In addition to this, the step promotes group study, which is good for a sense of cooperation, considerateness, and judgment. The study objective during this stage is improvement in problem solving and creative engineering design [7]. However, in reality, a robot for teaching tool 


\section{Issues in Information Systems}

Volume 13, Issue 2, pp.131-137, 2012

is very expensive. In addition to this, there exists no standard method and software to develop it. This means that each robot development has its own recipe, which prevents efficient education. This paper focuses on issues of RLearning and provides SMART education process for their solution.

\section{Intelligent Robot Simulation Environment}

Recent technology allows us to have a virtual robot rather than an actual one that emulates robot's sensor technology, motor control of a robot, and so on. To give an example, Microsoft provides MSRDS, a robot software platform that provides robot simulation environment in virtual 3d world. MSRDS is able to simulate full features of an actual robot [8]. Figure 3 compares a hardware-implemented robot to a software-simulated robot. As shown on the figure, both of a real robot and a software robot have similar look-and-feel and their features are almost same as well. Compared to a real robot, software robot, called Softbot, is more flexible and extensible. This paper designs SMART education process using MSRDS to fully entertain the benefit of Softbot while avoiding any drawbacks in using a real robot.

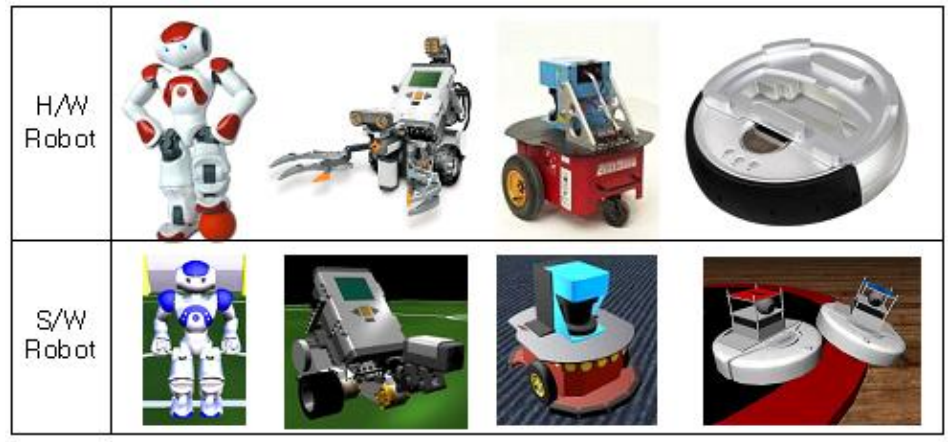

(a) Nao

(b) NXT Tribot

(c) Pioneer 3DX

(d) $x$-bot

$<$ Figure 3> Comparison of Hardware and Software Robot

MSRDS provides an easy way to realize virtual 3D world. Figure 4 shows an example of visual simulation environment having various objects and robots. This simulation environment consists of individual objects. Each object contains a manipulator that serves as robot's motor or sensor while exactly simulating physical interactions among objects [9][10].
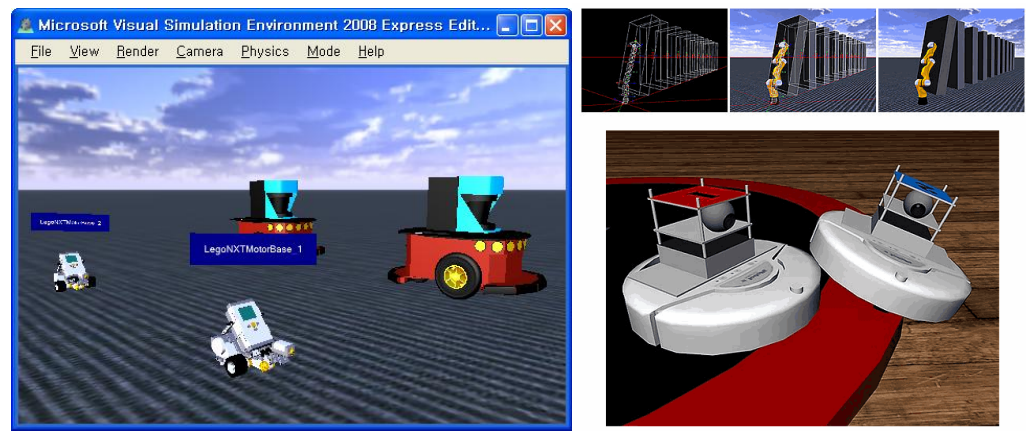

$<$ Figure 4> Robot Simulation Environment 


\section{Issues in Information Systems}

Volume 13, Issue 2, pp.131-137, 2012

\section{SMART Education Process Design}

The paper defines SMART education as an education with robot technology based on science, mathematics, and art. SMART education designs a robot based on scientific principles, programs it with mathematical algorithm, and artistically shape it. When implementing a robot, creative thinking and problem solving technique plays a critical role. Therefore, prior to an education, it is important to design teach-learning model after defining what is scientific thinking ability, mathematical application, and artistic design. In SMART teach-learning model, basic tasks are designed for senior students in an elementary school or junior students in a middle school. Under the consideration of the problem teach-learning process is implemented. Table 1 explains SMART education method using caterpillar's revolution principal. The benefit of SMART education is to help students learn very fast and effectively. In addition, the SMART education allows students to try out all the features of robot technology easily without any additional costs. Therefore, a robot used in the SMART education can be flexibly adapted to possible changes in class curriculum. Such flexibility opens a new chapter where students can implement their own robot creatively even not limited by the curriculum itself. This is critical in improving students' creativity and problem solving ability.

<Table 1> SMART Education Application Method

\begin{tabular}{|l|l|}
\hline Subject & \multicolumn{1}{|c|}{ Revolution Principle of Caterpillar } \\
\hline \multirow{3}{*}{ Science } & - Search for a difference between a wheel of a car and a wheel of a tank \\
- Investigation on revolution method of car and tank wheel \\
- Understanding on the relationship of speed and distance
\end{tabular}




\section{Issues in Information Systems}

Volume 13, Issue 2, pp.131-137, 2012

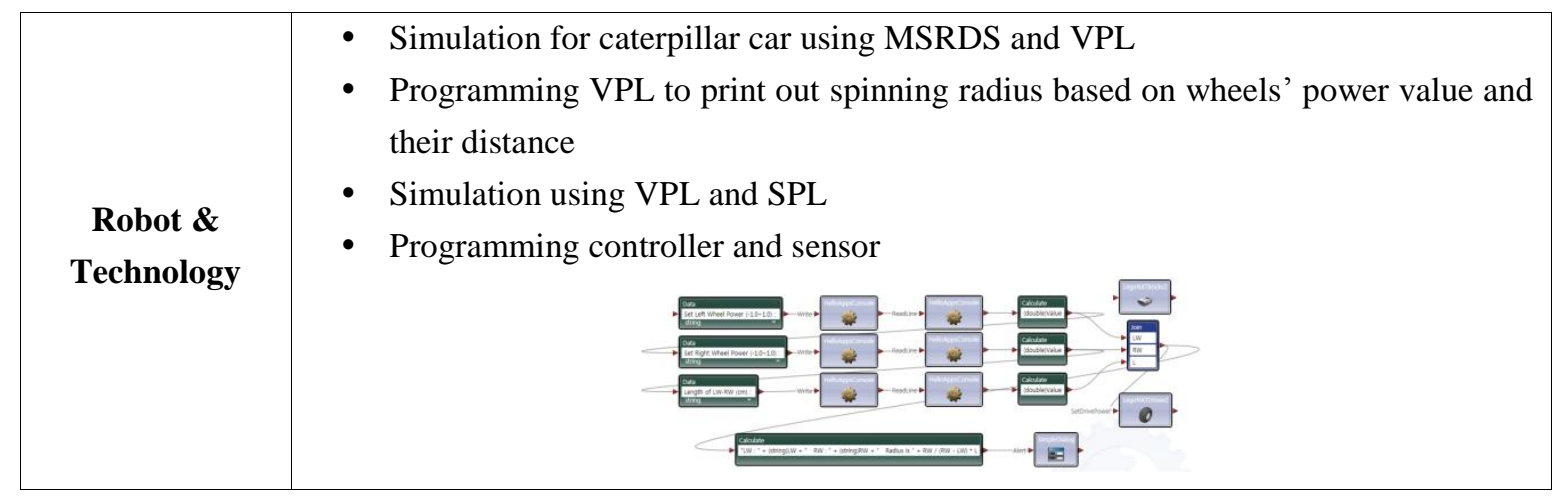

Figure 5 shows an example of SMART collaborative learning education. Students learn together what knowledge they need to master and apply in the field of science, math, art, and robot technology area. And, a teacher helps students perform experiments on how each area can be merged together and applied.

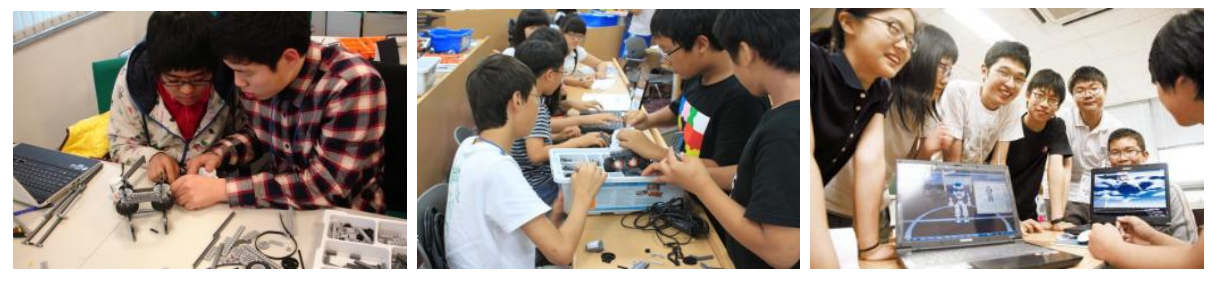

$<$ Figure 5> Example of SMART collaborative learning education

\section{RESULTS}

We performed experiment on the education effect and satisfaction of SMART education process presented in this paper. For the experiment, students in elementary school, middle school, high school, university are selected. When it comes to the students in elementary school, we choose 30 students enrolled in information genius class that a state government runs. As for the middle and high school students, 30 students were selected per each. We also selected 30 freshmen from a university.

Table 2 summarizes the experimental results in terms of type of students, number of people, education hours, and education subject. Students from elementary school designed an intelligent robot based on their own creative idea and programmed it following the guideline of SMART education process. In contrast, students from middle school, high school, and university, are given an abstract mission and they developed an intelligent robot by following the SMART learning analysis step.

Figure 6 explains results of students' satisfaction on the education effect after SMART education process. As shown in the figure, $93 \%$ of the students got very satisfied with the SMART and the SMART can be applicable to any levels of students. 


\section{Issues in Information Systems}

Volume 13, Issue 2, pp.131-137, 2012

<Table 2> Education Process Comparison on Learners

\begin{tabular}{|c|c|c|c|}
\hline Type of Students & $\begin{array}{c}\text { Number of } \\
\text { Students }\end{array}$ & Hours & Education Topic \\
\hline \hline $\begin{array}{c}\text { Elementary School } \\
\left(\mathbf{4}^{\text {th }}-\mathbf{6}^{\text {th }} \text { grade) }\right.\end{array}$ & 30 & $\begin{array}{c}26 \text { hours } \\
\text { (Education }+ \text { Practice) }\end{array}$ & Implement a creative robot \\
\hline $\begin{array}{c}\text { Middle School } \\
\left(\mathbf{1}^{\text {st }} \mathbf{3}^{\text {rd }} \text { grade) }\right.\end{array}$ & 30 & $\begin{array}{c}28 \text { hours } \\
\text { (Education }+ \text { Practice) }\end{array}$ & Abstract Mission \\
\hline $\begin{array}{c}\text { High School } \\
\left(\mathbf{1}^{\text {st }}-\mathbf{2}^{\text {nd }} \text { grade) }\right.\end{array}$ & 30 & $\begin{array}{c}28 \text { hours } \\
\text { (Education }+ \text { Practice) }\end{array}$ & Abstract Mission \\
\hline $\begin{array}{c}\text { University } \\
(\text { freshman })\end{array}$ & 30 & $\begin{array}{c}30 \text { hours } \\
\text { (Education }+ \text { Practice) }\end{array}$ & Abstract Mission \\
\hline
\end{tabular}
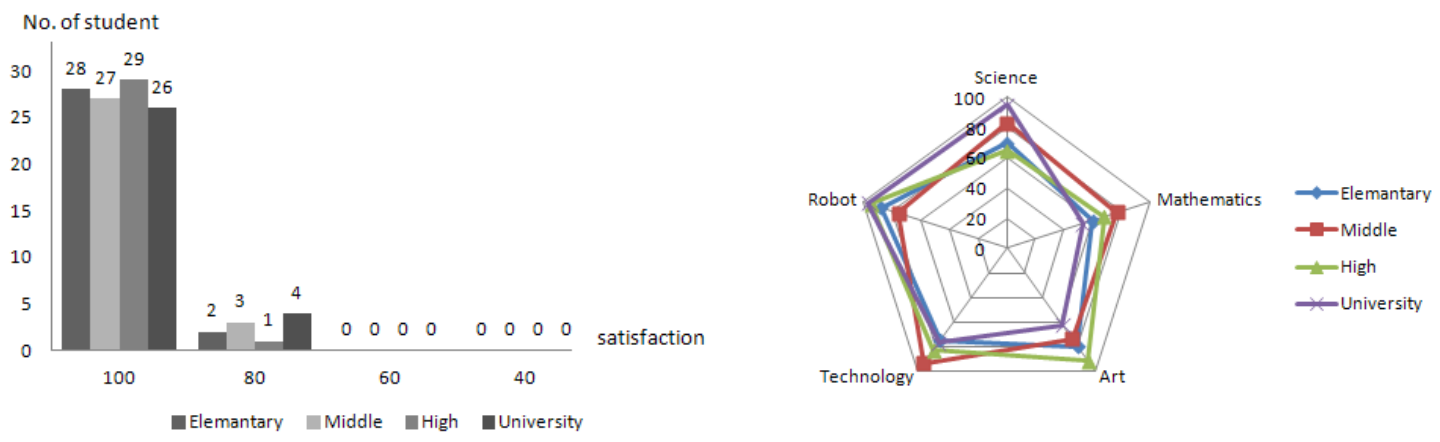

<Figure 6> SMART Education Satisfaction

\section{CONCLUSIONS}

This paper proposes the SMART education process using an intelligent robot. The paper also presents the methodology to implement a robot creatively, which was used in our experiments. The SMART education process promotes a learner to use a 3D virtual world, which results in excellent improvement in creativity and thinking process. Therefore, we expect that the SMART education process becomes a standard education process for next generation. In our following research, we will focus on how to provide a standard throughout a robot design process for the SMART education.

\section{ACKNOWLEDGMENT}

This work was supported by the Korean Government IT R\&D program of MKE/KEIT. [10035166, Development of Intelligent Tutoring System for Nursing Creative HR] 


\section{Issues in Information Systems}

Volume 13, Issue 2, pp.131-137, 2012

\section{REFERENCES}

1. Kuenzi, J., Matthews, C., and Mangan, B. (2006) Science, Technology, Engineering, and Mathematics (STEM) Education Issues and Legislative Options. Congressional Research Report. Washington, DC: Congressional Research Service.

2. SeongYong Hong. (2010) Learning Method using RDS for Creative Problem Solving. Journal of KIISE : Computing Practices and Letters.

3. Wicklein, R.C., (2006) 5 Good reasons for engineering design as the focus for technology education. The Technology Teacher, 65(7), 25-29.

4. Cordeiro, P., \& Campbell, B. (1996) Increasing the transfer of learning through problem-based learning in educational administration. ERIC Document Reproduction Service No. ED, 396-434.

5. M. Bennewitz, W. Burgard, S. Thrun, (2002) Finding and optimizing solvable priority schemes for decoupled path planning techniques for teams of mobile robots. Robotics and Autonomous Systems 41 (2-3), 89-99.

6. Breazeal, C., (2003) Emotion and sociable humanoid robots. International Journal of Human-Computer Studies, $59,119-155$.

7. N. Kubota, Y. Nojima, N. Baba, F. Kojima, and T. Fukuda, (2000) Evolving Pet Robot with Emotional Model. Proc. of Congress on Evolutionary Computation 2000 (CEC2000), 1231-1237.

8. Breazeal, Cynthia and Brian Scassellati., (1999) A Context-Dependent Attention System for a Social Robot. Proceedings of the Sixteenth International Joint Conference on Artificial Intelligence (IJCAI99), 1146-1151.

9. L. Hugues and N. Bredeche. (2006) Simbad: an autonomous robot simulation package for education and research. In Proceedings of the Ninth International Conference on the Simulation of Adaptive Behavior (SAB'06), Rome, Italy.

10. T. Braunl, H. Stolz, (1997) Mobile Robot Simulation with Sonar Sensors and Cameras. Simulation, vol. 69, no. 5, Nov, 277-282(6).

11. S. Y. Hong, (2008) A Study and Development of Intellectual Component based on Multi-Sensor for Intelligent Simulation Robot. Proc. of the 35th KIISE Fall Conference, vol.35, no.2 (B), 6-10.

12. S. Y. Hong, E. G. Seo, H. J. Choi, (2008) A Study on Development of MSF Intelligent Robot Simulation based 3D using MSRDS. Proc. of the 30th KIPS Fall Conference, vol.15, no.2, 452-454.

13. Microsoft Robotics - http://msdn.microsoft.com/en-us/robotics/default.aspx

14. Kyle Johns, Taylor Trevor, (2008) Microsoft ${ }^{\circledR}$ Robotics Developer Studio. Wrox Press. 